\title{
Anatomical study of the suprascapular notch: quantitative analysis and clinical considerations for suprascapular nerve entrapment
}

Ajay $\underline{K u m a r}^{1}$, мBвS, мs, Anu Sharma ${ }^{1}$, MBBS, Ms, Poonam $\underline{\text { Singh }}^{1}$, MBBS, MS

INTRODUCTION Detailed anatomical knowledge of the suprascapular notch (SSN) is important for the management of entrapment neuropathy and interventional procedures. The objective of the present study was to collect data on the morphological features and anatomical variations of the SSN in an Indian population.

METHODS We studied 268 human scapulae of unknown sex (126 right-sided, 142 left-sided) taken from the Department of Anatomy, Dayanand Medical College and Hospital, India. SSNs were classified as either type I, II, III, IV or V, based on the shape of the inferior border of the incisura, and comparison of the SSN's vertical and transverse diameters. The shape of the SSN (i.e V-or U-shaped), if present, was also recorded.

RESULTS Type II SSN was the most common (50.00\%), followed by type I, type IV and type III (32.46\%, 9.70\% and $7.84 \%$, respectively). For right-sided type II SSNs, the transverse and vertical diameters were $9.1 \pm 3.2 \mathrm{~mm}$ and $5.2 \pm 1.9 \mathrm{~mm}$, respectively, while those for left-sided type II SSNs were $9.2 \pm 2.4 \mathrm{~mm}$ and $5.1 \pm 1.8 \mathrm{~mm}$, respectively. Generally, the transverse diameter of type II SSN was found to be greater than that of type III SSN. The incidence of $\mathrm{U}$-shaped SSN was $51.49 \%$, while that of $\mathrm{V}$-shaped SSN was $2.99 \%$.

CONCLUSION This study of the morphometrical characteristics and anatomical variations of SSN provides an anatomical database of SSN in the Indian context. This database will be of use in surgical procedures, as the information can be used to ensure adequate access to and complete decompression of the suprascapular nerve.

Keywords: scapula, suprascapular nerve entrapment, suprascapular notch

\section{INTRODUCTION}

The suprascapular notch (SSN) is a depression in the lateral part of the superior border of the scapula, which runs medial to the coracoid process (Fig. 1). The suprascapular nerve (SN) is a large branch of the superior trunk that runs laterally deep to the trapezius and omohyoid, and enters the supraspinous fossa through the SSN, inferior to the superior transverse scapular ligament (STSL). It then runs deep to the supraspinatus and curves around the lateral border of the scapular spine with the suprascapular artery to reach the infraspinous fossa, where it branches to the supraspinatus and articular rami of the shoulder, and the acromioclavicular joint. ${ }^{(1)}$ The $\mathrm{SN}$ is liable to compression when crossing the osteofibrous canal at the SSN. Anatomical variations of the SSN are a possible cause of SN entrapment, especially in individuals involved in repetitive and forceful overhead activities (e.g. volleyball players and baseball pitchers). (2-5) While aberrant course of the suprascapular artery through the SSN can lead to SN compression, ${ }^{(6)}$ anomalous STSL is the most recognised predisposing factor for $\mathrm{SN}$ compression at the SSN; this has been demonstrated in both anatomy dissections and the clinical setting. ${ }^{(7-9)}$

Clinically, SN entrapment is characterised by pain in the posterolateral region of the shoulder, and atrophy of the infraspinatus and supraspinatus muscles. While SN

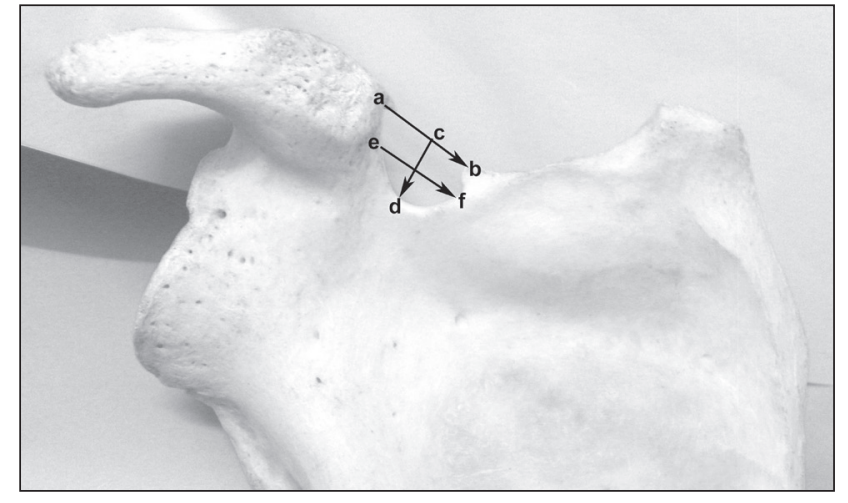

Fig. 1 Photograph shows the suprascapular notch of a human scapula. a-b: imaginary line that joins the superior corners of the incisura; $c-d$ : maximal vertical diameter of the incisura; $e-f$ : maximal transverse diameter of the incisura

entrapment plays a crucial role in shoulder pain, its possible role is often overlooked in the differential diagnosis of shoulder discomfort. ${ }^{(10)}$ The SSN is bridged by the STSL, which is sometimes ossified, transforming the SSN into a foramen. The SN passes through this foramen to the supraspinous fossa. ${ }^{(11)}$

\section{METHODS}

The present study was conducted over a period of one year. It included the analysis of 126 right-sided and 142 left-sided dry adult human scapulae of unknown sex belonging to an Indian

${ }^{1}$ Department of Anatomy, Dayanand Medical College and Hospital, Ludhiana, India

Correspondence: Dr Anu Sharma, Professor, Department of Anatomy, Dayanand Medical College and Hospital, Ludhiana, Punjab 141001, India. anuashwani2003@yahoo.com 

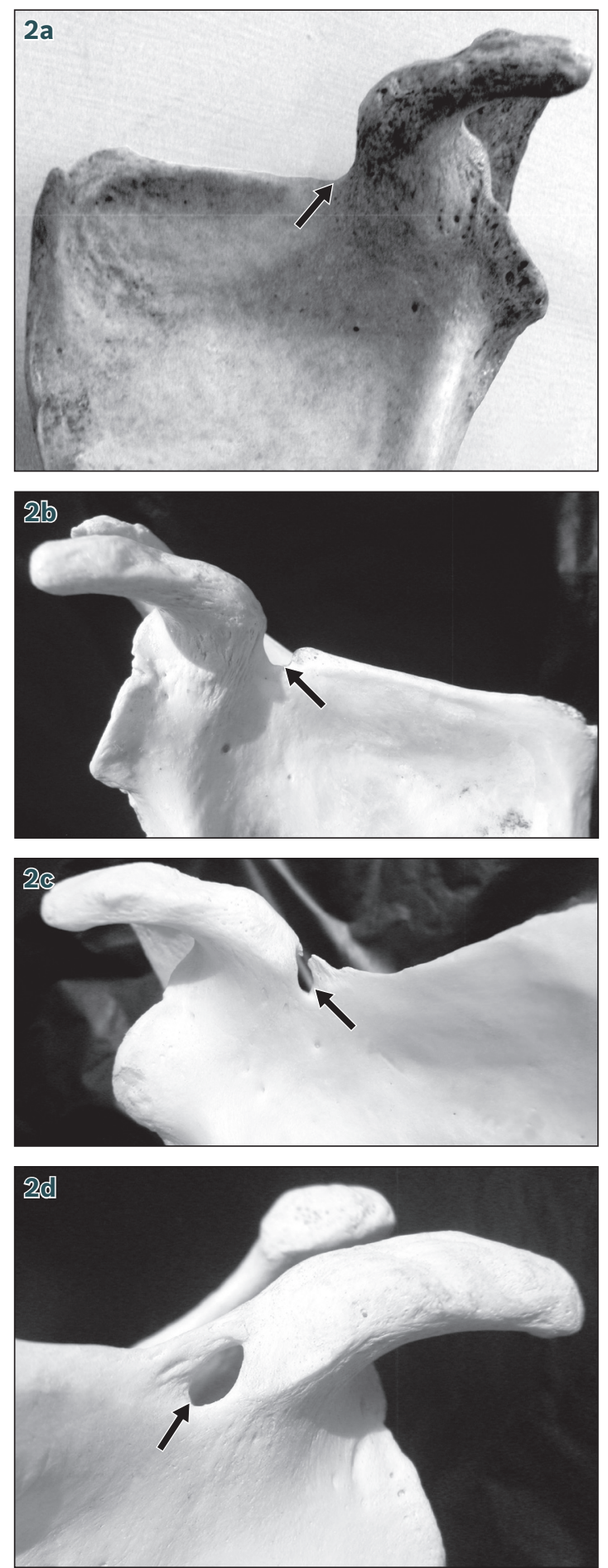

Fig. 2 Photographs of human scapulae show (a) type I; (b) type II; (c) type III; and (d) type IV suprascapular notches (arrows). Note the completely formed bony suprascapular foramen in type IV.

population. Only bones that were intact and free from any pathological or congenital anomalies were used. Anatomic measurements accurate to $0.1 \mathrm{~mm}$ were taken using a vernier calliper. Appropriate statistical analysis was done whenever applicable.

The SSNs were classified into five groups based on the shape of the inferior border of the incisura, as well as comparison of the vertical and transverse diameters of the SSN (Fig. 1). ${ }^{(12)}$ The five groups were as follows: (a) type I: no discrete SSN (Fig. 2a); (b) type II: SSN has a greater transverse diameter than
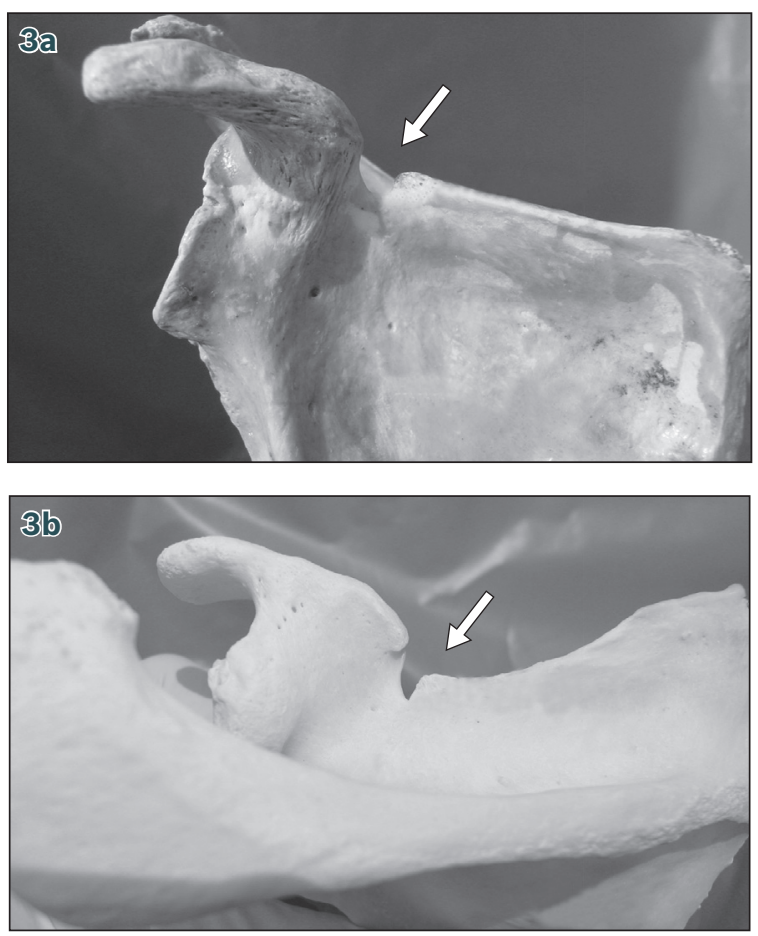

Fig. 3 Photographs of human scapulae show (a) a U-shaped suprascapular notch (arrow); and (b) a V-shaped suprascapular notch (arrow).

vertical diameter (Fig. 2b); (c) type III: SSN has a greater vertical diameter than transverse diameter (Fig. 2c); (d) type IV: SSN with a completely formed bony suprascapular foramen (Fig. 2d); and (e) type V: SSN with foramen and incisura. The diameters could not be measured in types IV and V SSNs due to the ossified STSL. The SSNs were also classified according to shape, as either (a) U-shaped: SSN with approximately parallel sides and a rounded base (Fig. 3a); or (b) V-shaped: SSN with medial and lateral sides that converge toward a narrow base (Fig. 3b).

\section{RESULTS}

A total of 268 scapulae were analysed in the present study. SSNs were classified into five groups, of which the most prevalent was type II (50.00\%), followed by type I (32.46\%), type IV (9.70\%) and type III (7.84\%) (Table I). Quantitative measurements of types II and III SSNs were taken and tabulated. Metric measurements of types I and IV SSNs could not be taken because type I SSN does not have a discrete notch and type IV SSN has a completely formed bony suprascapular foramen. Type V SSN was not found in our study. The mean \pm standard deviation of each parameter, and the shape of each SSN are shown in Tables I and II, respectively.

In our study, $32.46 \%$ of the scapulae were classified as type I SSN (Fig. 2a). These SSNs did not appear to have a notch, as their superior border presented with a somewhat concave pattern that is without depth, at the midsection where the SSN should have been, thus confirming its absence. The measurements of the transverse and vertical diameters of the right- and left-sided scapulae with types II and III SSNs 
Table I. Type and measurements of the suprascapular notches (SSNs) $(n=268)$.

\begin{tabular}{lccc}
\hline Type of SSN & Proportion (\%) & \multicolumn{2}{c}{ Mean \pm SD (mm) } \\
\cline { 3 - 4 } & & $\begin{array}{c}\text { Transverse } \\
\text { diameter }\end{array}$ & $\begin{array}{c}\text { Vertical } \\
\text { diameter }\end{array}$ \\
\hline Type I & & & \\
Right-sided & $39 / 126(30.95)$ & NA & NA \\
Left-sided & $48 / 142(33.80)$ & NA & NA \\
Total & $87 / 268(32.46)$ & - & - \\
Type II & & & \\
Right-sided & $60 / 126(47.62)$ & $9.1 \pm 3.2$ & $5.2 \pm 1.9$ \\
Left-sided & $74 / 142(52.11)$ & $9.2 \pm 2.4$ & $5.1 \pm 1.8$ \\
Total & $134 / 268(50.00)$ & - & - \\
Type III & & & \\
Right-sided & $13 / 126(10.32)$ & $5.9 \pm 3.2$ & $7.1 \pm 1.9$ \\
Left-sided & $8 / 142(5.63)$ & $7.4 \pm 2.4$ & $9.1 \pm 1.8$ \\
Total & $21 / 268(7.84)$ & - & - \\
Type IV & & & \\
Right-sided & $14 / 126(11.11)$ & NA & NA \\
Left-sided & $12 / 142(8.45)$ & NA & NA \\
Total & $26 / 268(9.70)$ & - & - \\
\hline TA & & &
\end{tabular}

NA: not available; SD: standard deviation

Table II. Shape of the suprascapular notches $(n=268)$.

\begin{tabular}{lccc}
\hline Shape & \multicolumn{3}{c}{ Proportion (\%) } \\
\cline { 2 - 4 } & Right-sided & Left-sided & Total \\
\hline U-shaped & $63 / 126(50.00)$ & $75 / 142(52.82)$ & $138 / 268(51.49)$ \\
V-shaped & $4 / 126(3.17)$ & $4 / 142(2.82)$ & $8 / 268(2.99)$ \\
\hline
\end{tabular}

are shown in Table I. For right-sided type II SSNs, the mean transverse and vertical diameters were $9.1 \pm 3.2 \mathrm{~mm}$ and $5.2 \pm 1.9 \mathrm{~mm}$, respectively, while those for left-sided type II SSNs were $9.2 \pm 2.4 \mathrm{~mm}$ and $5.1 \pm 1.8 \mathrm{~mm}$, respectively. For right-sided type III SSNs, the mean transverse and vertical diameters were $5.9 \pm 3.2 \mathrm{~mm}$ and $7.1 \pm 1.9 \mathrm{~mm}$, respectively, while the corresponding measurements for the left-sided type III SSNs were $7.4 \pm 2.4 \mathrm{~mm}$ and $9.1 \pm 1.8 \mathrm{~mm}$, respectively. The transverse diameters of type II SSNs were found to be greater than those of type III SSNs in our study. Of all the scapulae examined, $51.49 \%$ were $U$-shaped and $2.99 \%$ were $\mathrm{V}$-shaped (Table II).

\section{DISCUSSION}

Complete absence of the SSN has been suggested as a predisposing factor for suprascapular entrapment neuropathy (i.e. SN entrapment). ${ }^{(13)}$ The various shapes and sizes of the SSN may also play a role in SN entrapment, ${ }^{(14)}$ as narrow SSNs have been found in patients with $\mathrm{SN}$ entrapment. ${ }^{(15)}$ While previous studies have classified the shapes of SSN using certain mathematical formulas, ${ }^{(8,12,15)}$ in this study, we used a simple and reproducible classification system ${ }^{(12)}$ to document the various types of SSN. This system uses specific geometrical parameters that distinguish one type of SSN from another. Furthermore, this system for quantitative measurements is easier to comprehend than other classification systems. ${ }^{(12)}$

In the present study, we observed a total of 87 (32.46\%) type I SSNs among the 268 specimens. Scapulae with type I SSN can be considered as having no SSN or SSN-absent. ${ }^{(12)}$ At the location where the SSN should have been present, the bone appeared thinner and more translucent than in other parts. This was different from that seen in scapulae with SSNs that were located at the junction of medial two-thirds and the lateral third, just medial to the base of the coracoid process. The number of type I SSNs in our study of Indian scapulae is greater than that reported in studies of Nigerian ${ }^{(16)}$ and Chinese ${ }^{(17)}$ populations. This observation can be explained by racial differences.

The incidence of type II SSN was $50.00 \%$ in our study. Type II SSN was also found to be the most common type of SSN in previous studies. ${ }^{(16,17)}$ In the present study, the incidence of type III SSN was $7.84 \%$, which is lower than that reported in Chinese and Western populations. ${ }^{(17)}$ This difference may be grounded in ethnic and racial differences. Type IV SSN was present in $9.70 \%$ of the scapulae in the present study. The literature shows that the incidence of type IV SSN varies between $3.7 \%$ and $12.5 \% .^{(8,9,12,15)}$ This variability may be related to the different methods of classification and the genetic differences between the populations studied. There was total absence of type V SSN in our sample of scapulae, which is contrary to that reported in previous studies. ${ }^{(8,12,18)}$ In animals, the SSN is frequently bridged by a bone rather than a ligament. In humans, however, if the conversion of SSN into foramina occurs, it is due to the ossification of the STSL. ${ }^{(13)}$ We observed both $U$ - and V-shaped SSNs in our study, with U-shaped SSNs being more common $(51.49 \%)$ than V-shaped SSNs (2.99\%). While SN entrapment is more likely to be associated with the narrow V-shaped notch, ${ }^{(19)}$ no direct correlation between notch-shape and $\mathrm{SN}$ entrapment has been advocated by clinicians. ${ }^{(20)}$

In conclusion, our quantitative and qualitative study on the morphology of SSN provides well-sorted data regarding the incidence of various types of SSN in an Indian population. The size of the SSN is considered to play a part in the predisposition for $\mathrm{SN}$ entrapment. A small notch gives rise to a larger chance of nerve impingement than a large notch. ${ }^{(15)}$ In the present study, the most common type of SSN observed was type II SSN, which has a lower chance of $\mathrm{SN}$ entrapment compared to the other types of SSN (i.e. types III, IV and V). No scapula with type V SSN was found in our study. The metrical values and precise localisation of the $\mathrm{SSN}$, as well as information on the anatomical variants of the SSN, are important in understanding $\mathrm{SN}$ entrapment syndrome and surgical decompression of $\mathrm{SN}$. Therefore, the present study on SSNs of scapulae from an Indian population may be of interest to both clinicians and anatomists.

\section{REFERENCES}

1. Berry MM, Stranding SM, Bannister LH, eds. Nervous System. In: Gray H, Williams PL, Bannister LH, eds. Gray's Anatomy: the anatomical basis of medicine and surgery. 38th ed. Edinburgh: Churchill Livingstone, 1995.

2. Gelberman RH, Verdeck WN, Brodhead WT. Supraclavicular nerveentrapment syndrome. J Bone Joint Surg Am 1975; 57:119.

3. Holzgraefe M, Kukowski B, Eggert S. Prevalence of latent and manifest suprascapular neuropathy in high-performance volleyball players. Br J Sports Med 1994; 28:177-9 
4. Padua L, LoMonaco M, Padua R, et al. Suprascapular nerve entrapment. Neurophysiological localization in 6 cases. Acta Orthop Scand 1996; 67:482-4.

5. Post M, Mayer J. Suprascapular nerve entrapment. Clin Orthop Relat Res 1987; 223:126-36.

6. Tubbs RS, Smyth MD, Salter G, Oakes WJ. Anomalous traversement of the suprascapular artery through the suprascapular notch: a possible mechanism for undiagnosed shoulder pain? Med Sci Monit 2003; 9:116-9.

7. Cohen SB, Dines DM, Moorman CT. Familial calcification of superior transverse scapular ligament causing neuropathy. Clin Orthop Relat Res 1997; 334:131-5.

8. Ticker JB, Djurasovic M, Strauch RJ, et al. The incidence of ganglion cysts and other variation in anatomy along the course of the suprascapular nerve. J Shoulder Elbow Surg 1998; 7:472-78.

9. Bayramoğlu A, Demiryürek D, Tüccar E, et al. Variations in anatomy at the suprascapular notch, possibly causing suprascapular nerve entrapment: an anatomical study. Knee Surg Sports Traumatol Arthrosc 2003; 11:393-8

10. Zehetgruber H, Noske H, Lang T, Wurning C. Suprascapular nerve entrapment. A meta-analysis. Int Orthop 2002; 26:339-43.

11. Standring SM, Ellis $\mathrm{H}$, Healy JC, et al. Pectoral girdle and Upper Limb. In: Standring SM, ed. Gray's Anatomy, 39th ed. Edinburgh: ChurchillLivingstone, 2005:847.
12. Natsis K, Totlis T, Tsikaras P, et al. Proposal for classification of suprascapular notch: a study on 423 dried scapulas. Clin Anat 2007; 20:135-9.

13. Khan MA. Complete ossification of the superior transverse scapular ligament in an Indian male adult. Int J Morphol 2006; 24:195-6.

14. Dunkelgrun M, lesaka K, Park SS, Kummer FJ, Zuckerman JD. Interobserve reliability and intraobserver reproducibility in suprascapular notch typing. Bull Hosp Jt Dis 2003; 61:118-22.

15. Rengachary SS, Burr D, Lucas S, et al. Suprascapular entrapment neuropathy: a clinical, anatomical, and comparative study. Part 2: anatomical study. Neurosugery 1979: 5:447-51.

16. Ofusori DA, Ude RA, Okwuonu CU, Adesanya OA. Complete absence of suprascapular notch in a Nigerian scapula: A possible cause of suprascapular nerve entrapment. Int J Shoulder Surg 2008; 2:85-6.

17. Wang HJ, Chen C, Wu LP, et al. Variable morphology of suprascapular notch: an investigation and quantitative measurements in Chinese population. Clin Anat 2011; 24:47-55.

18. Hrdlička A. The scapula: Visual observations. Am J Phys Anthropol 1942; 29:73-94.

19. Iqbal K, Iqbal R, Khan SG. Anatomical variations in shape of suprascapular notch of scapula. J Morphol Sci 2010; 27:1-2.

20. Alon M, Weiss S, Fishel B, Dekel S. Bilateral suprascapular nerve entrapment syndrome due to anomalus transverse scapula ligaments. Clin Orthop Relat Res 1988; 234:31-3. 